\title{
Educació científica humanitzada
}

Ferah Özer (ferahozer@yahoo.com)

Abant Izzet Baysal University, Bolu, Turkey

Anna Garrido (agarridoespeja@gmail.com)

Centre de Recerca per a l'Educació Científica i Matemàtica (CRECIM). Universitat Autònoma de Barcelona.

L'article analitza els fonaments de la ciència a l'escola $i$ les seves interrelacions amb el concepte de Naturalesa de les ciències mitjançant l'ús dels seus antecedents històrics $i$ fent referència a la història de la ciència. A partir de l'explicació de relacions i conceptes, l'article descriu principalment com l'ensenyament de la ciència pot ser o hauria de ser més humanitzada per ser capaç d'ensenyar eficaçment als alumnes.

Paraules clau: Educació científica humanitzada, naturalesa de les ciències.

The article discusses the foundations of school science and its interrelations with the concept of Nature of Science by using its historical backaround and refers to history of science. By explaining the relationships and concepts, the article describes mainly how the science education can or should be more humanized to be able to teach to pupils.

Keywords: Humanized scientific education, Nature of science

\section{ELS INICIS DE L'EDUCACIÓ EN CIÈNCI- ES ALS EUA I AL REGNE UNIT: CANVIS EN LES POLÍTIQUES}

Els primers treballs i progressos més dedicats a la millora de l'educació científica a les escoles es van apreciar inicialment als Estats Units d'Amèrica $i$ al Regne Unit, per diverses raons. En ambdós països, les iniciatives més importants per a l'educació en ciències van començar al segle XIX $\mathrm{i}$ inicialment van afectar principalment a les institucions d'educació de masses: les escoles per a infants.

A finals del segle XVIII, l'educació científica per a nens als Estats Units estava plena d'experiències manipulatives i consistia en l'observació directa i el contacte amb els fenòmens naturals. Aquestes estructures i mètodes es basaven en idees de Benjamin Franklin dels anys 1750, per instruir una generació més pràcticament informada en àmbits com l'agricultura, la navegació i la topografia, així com en base a la política de educar "americans" a les escoles comunes (Atkin \& Black, 2007). Per tant, els llibres s'estructuraven en funció d'aquestes idees de fons. Per exemple, un llibre podia explicar una història ambientada en una família en què el focus de les activitats i converses, entre infants i adults, era en temes com els planetes, el cicle de l'aigua o l'estructura d'una mosca domèstica. En aquests relats hi havia també una formació moral oculta per als nens, a través d'alguns exemples o històries de la vida familiar on s'obeïen les regles o a través de la utilització de faules.

A finals del segle XIX es va començar a donar importància als nens com a participants actius del seu propi aprenentatge. Així, els nens estudiaven i descrivien els objectes portats a classe. Aquests moviments es poden considerar com les arrels del constructivisme. A més, al 1918 els Principis Cardinals d'Educació van ser publicats a nivell de secundària mostrant un programa continu des de preescolar fins a la universitat emfatitzant la millora de les capacitats intel-lectuals dels alumnes. L'objectiu més important era millorar la comprensió de la utilitat de la ciència en la societat. S'advocava que els programes de ciències de secundària ajudaven als estudiants a comprendre que la ciència és un tipus d'indagació que consisteix en la "resolució de problemes". 
El Ilançament del Sputnik per la Unió Soviètica l'any 1959 va ser un esdeveniment clau a la història dels EEUU. Després d'aquella data, el Congrés dels EUA va assignar una gran quantitat de fons per a la millora de l'educació científica i matemàtica, per tal de competir amb l'èxit de la Unió Soviètica (Atkin \& Black, 2007). Així, als anys 1950, la National Science Foundation (NSF) va agrupar 35 científics, psicòlegs i desenvolupadors curriculars per unir la seva feina amb un suport impressionant. Jerome Brume va ser el responsable de preparar el document posterior a la conferència. Amb el suport de la NSF principalment, es van desenvolupar projectes en biologia, química i ciències de la terra a nivell de secundària $i$ alguns nivells de primària (Atkin \& Black, 2007). Cap altre moviment curricular en ciències des del 1955 als anys 1970 va involucrar de manera central als científics més reconeguts de la nació per treballar a nivell de primària $\mathrm{i}$ secundària. Els primers resultats d'aquest moviment van ser esperançadors. El percentatge de persones que completaven els 4 anys de batxillerat durant aquells anys va augmentar del $25 \%$ al $75 \%$ i els EUA es va convertir en el primer país en posar un home a la lluna. Després de Sputnik, el sistema educatiu estatunidenc havia de respondre per aconseguir una força de treball futur millor.

Les polítiques per estructurar l'educació eren diferents al Regne Unit que als EUA, ja que aquestes es van construir més per influència de les universitats. Les universitats requerien certificats de finalització escolar i les escoles estaven enfocades en aconseguir l'èxit de l'alumnat en aquests tests, i per tant el currículum va anar canviant per afrontar aquest repte. Als anys 1910, la influència de Montessori, Dewey i Froebel va començar a donar atenció al desenvolupament físic, mental i emocional dels infants. Al llarg dels anys 50-60A els ministres d'educació van anar impulsant un moviment centrat en l'alumnat, en el qual els nens començaven a ser immersos en jocs no guiats, en observacions, formulació de preguntes, i revisió d'hipòtesis.

\section{ELS OBJECTIUS DE L'EDUCACIÓ CIEN- TíFICA}

La pregunta sobre quines són les funcions de l'ensenyament en ciències s'ha debatut de manera extensa en els últims anys tant al Regne Unit com internacionalment (Black and Atkin 1996; Millar and Osborne 1998 cited by Reiss 2001). De manera creixent s'ha acordat que l'educació científica escolar hauria de donar servei a les necessitats de tots els infants. Vivim en una època on la ciència té una rellevància cultural i tecnològica enorme, i l'educació científica té el potencial d'ajudar als alumnes a participar en el món de la ciència i alhora entendre tant les seves potencialitats com les seves limitacions.

Filòsofs com Hirst (Hirst \& Peters 1970) i Phenix (1964) defensaven que la ciència té unes característiques distintives que no es troben en cap altra disciplina. Hirst va suggerir que la ciència havia de ser ensenyada conjuntament amb altres formes de coneixement, per permetre als infants esdevenir éssers humans racionals, així com que hauríem de tenir com a objectiu oferir als alumnes una varietat de disciplines, inclosa la ciència, que puguin arribar a utilitzar de manera apropiada en diferents contextos.

Les ciències son significativament diferents de qualsevol altra matèria de l'ensenyament a l'escola primària. A diferència de les altres matèries, la ciència dóna als estudiants la oportunitat de fer hipòtesis i posar a prova les seves idees a través de la indagació. Per exemple, les autoritats educatives australianes van exemplificar la distinció de la ciència en termes de com estimula la curiositat dels estudiants pel món natural. Encara més, les ciències poden promoure la participació activa dels estudiants en el mètode científic com una forma de pensament crític i creatiu que involucra l'argumentació, la modelització i l'avaluació // la producció, avaluació i comunicació del coneixement (JimenezAleixandre, 2012). A través de la ciència, diuen, "els alumnes aprenen a qüestionar i a discutir temes i aspectes científics" (QCA, 1999)

El debat actual entorn els objectius de l'educació en ciències és profund i fundamental. Per què els nens haurien d'aprendre ciències?

Primer de tot, existeix una dimensió política, instada per la recerca en relació a dirigir i controlar el currículum escolar per tal de promoure una millor comprensió pública de la ciència, incrementar l'alfabetització científica i per tant millorar la comprensió de la ciència en relació a una ciutadania democràtica. La gent està envoltada de ciència i els governs necessiten prendre decisions basades en la investigació científica, per tant els alumnes haurien d'aprendre suficient ciència com per participar en la presa de decisions democràtica de manera informada. Això va ser un canvi respecte simplement una visió d'aprendre ciències per entendre el món a una visió de la ciència com una activitat humana carregada de valors i com una necessitat per entendre els temes actuals en un context polític. Per 
aquest motiu, l'alfabetització científica es veu com l'objectiu principal de l'ensenyament de les ciències i és considerada més una preparació per a la ciutadania que una preparació per a una vida científica professional.

Més recentment, els criteris generals del Departament d'Educació i Ciència dels EUA (DES, 1985) argumentaven que "tots els programes educatius haurien d'estar dissenyats per ajudar als estudiants a entendre la relació de la matèria amb altres àrees d'estudi i la seva rellevància per la seva vida". Això ha sigut interpretat com que cal el desenvolupament d'un interès informat dels temes científics per arribar a ser ciutadans segurs de si mateixos en un món cientifico-tecnològic que té en compte les influències i limitacions socials, econòmiques, mediambientals, ètiques i culturals de la ciència.

Una segona visió és que els nens necessiten aprendre ciències per tal de comprendre el món que els envolta. Aquesta és una visió que considera la ciència especialment com un sistema de veritats ben establertes i no controvertides, i que l'alumnat necessita conèixer per a comprendre el món en el qual viu.

D'acord amb la literatura trobada (Milner 1986; Thomas and Durant 1987; Millar 1996, citats per Driver et al 1996), es poden resumir els objectius de l'educació científica en quatre arguments principals:

- L'argument utilitari: aquesta visió planteja que els alumnes es poden beneficiar de l'aprenentatge de les ciències a nivell pràctic. El coneixement científic els permet, per exemple, connectar un endoll o reparar el cotxe, i per tant es planteja com una manera d'enfrontar-se als problemes de la vida del dia a dia a través de I'habilitat de solucionar problemes.

- L'argument econòmic: aquest és l'argument en el qual una societat tecnològicament avançada necessita un subministrament constant de científics per mantenir la seva base econòmica $i$ la competitivitat internacional. Existeix una llarga tradició dins d'aquesta visió instrumental en la qual es defensa que un país necessita científics per poder competir internacionalment. No obstant això, no està clara la relació directa entre el nombre de científics i enginyers i l'èxit d'un país econòmicament.

- L'argument cultural: la comprensió de la cultura de la ciència requereix una mica d'història de la ciència, d'ètica de la ciència, d'argument de ciència i de controvèrsia científica que donin més èmfasi a la dimensió humana i menys èmfasi en la ciència com un cos de coneixement cosificat.

- L'argument democràtic: per últim, l'argument democràtic, discutit en els paràgrafs anteriors, posa èmfasi en la discussió de controvèrsies socio-científiques, la qual milloraria si els nostres ciutadans tinguessin una actitud més crítica cap a la ciència. Una societat democràtica requereix de la participació activa de tots els ciutadans i només pot ser assolida si els individus tenen al menys una comprensió de la ciència que els porti a ser més crítics.

\section{EDUCACIÓ EN CIÈNCIES HUMANITZA- DA}

Segons Jacques Delors (1996), expresident de la Comissió Europea, l'educació està en el cor del desenvolupament de les persones com a individus $i$ de la comunitat, i la seva missió és permetre que cada persona, sense excepció, pugui desenvolupar tots els talents al màxim i adonar-se del seu potencial creatiu, incloent la responsabilitat sobre la seva pròpia vida i l'assoliment dels objectius personals per funcionar amb eficàcia en una família, com a ciutadà o com un membre productiu de la societat. Per aquesta raó és necessari, entre d'altres coses, familiaritzar-se des d'una edat primerenca amb la ciència i els usos de la ciència, i amb la difícil tasca d'assimilar el progrés de la societat de manera que la identitat i la integritat humanes siguin plenament respectades.

A més, també hi ha la necessitat de replantejar i ampliar el concepte d'educació permanent. Aquesta no només s'ha d'adaptar als canvis en la naturalesa de la feina, sinó que ha de constituir també com un procés continu de formació d'éssers humans complets - els seus coneixements i aptituds, així com la capacitat de pensar de manera crítica i la capacitat d'actuar. L'educació hauria de permetre a la gent desenvolupar la consciència de si mateixos i del seu entorn i animar-los a jugar el seu paper social tant a la feina com en la comunitat.

Com s'indica a les "Necessitats Bàsiques d'Aprenentatge", produït al 1990 a la Conferència Mundial sobre Educació per a Tothom (Jomtien, Tailàndia, 1990):

"Aquestes necessitats inclouen tant les eines essencials per a l'aprenentatge (com l'alfabetització, l'expressió oral, el càlcul, la resolució de problemes) com els continguts d'aprenentatge bàsics (coneixements, habilitats, valors $i$ actituds) necessaris pels éssers humans per poder sobreviure, per 
desenvolupar plenament les seves capacitats, per viure $i$ treballar amb dignitat, participar plenament en el desenvolupament, millorar la qualitat de la seva vida, prendre decisions fonamentades $i$ continuar aprenent." (Declaració Mundial sobre Educació per a Tothom, l'art. 1, paràgraf 1 , citat per Delors, 1996).

Per tant, l'educació científica no hauria d'ignorar la relació entre la ciència, la tecnologia i la societat. És en aquestes relacions on rau la rellevància de la ciència i en un món així, l'educació científica ha de reflectir una trinitat d'interessos: Productes, Processos i Persones. Quan ho fa, es converteix en una educació científica humanitzada. Per exemple, un dels objectius d'alguns que volen humanitzar l'ensenyament de la ciència es dirigeix cap a l'educació moral. De fet, aspectes morals es manifesten en gairebé qualsevol forma d'ensenyament de les ciències i quan l'objectiu és humanitzar, el què es pretén és alhora fer a la gent més racional i humana.

Mentre que l'ensenyament de les ciències humanitzat pot ser vist com una forma d'assenyalar el valor cultural de l'educació científica, mostrant la seva pertinència, importància i significat per a la gent, a la pràctica, també significa incloure, d'una manera o altra, la Història de la Ciència. Per John Brown, la història, el romanç i la biografia de la ciència eren components importants de l'ensenyament de la ciència si es volia fer veure i entendre el seu valor cultural (Brown, 1925, citat per Newton, 1988).

\section{LA HISTÒRIA DE LA CIÈNCIA I L'EDUCACIÓ CIENTÍFICA HUMANITZA- DA}

En les primeres dècades del $S . X X$, la ciència escolar es veia com l'ensenyament d'una sèrie de passos establerts sobre la història de la ciència i la vida dels científics.

JD Bernal (1946, citat per Newton, 1988) va emfatitzar, per la seva banda, els objectius socials. L'educació científica, va escriure, ha de "proporcionar la comprensió dels efectes de la ciència en la societat i ha de permetre als ciutadans criticar o valorar aquests efectes". Això es podria aconseguir fent de la història de la ciència una part vital de l'ensenyament de les ciències. Segons Burke (1978) els alumnes han d'aprendre sobre la història de la ciència per poder entendre els processos d'innovació i la seva influència en la ciència i la societat.
James Bryant Conant, que va ser un dels primers empresaris coneguts per proposar que s'inclogués la història de la ciència en als plans d'estudis de ciència de primària $i$ secundària $i$ en els llibres de text, va posar èmfasi en que els ciutadans només podien entendre com funciona la ciència mitjançant l'examen dels processos històrics i el desenvolupament d'aquesta.

Després de les discussions sobre la història de la ciència en els anys 1960 i 1980 i la seva importància, hi va haver altres intents sobre com incloure la història de la ciència en els plans d'estudis i les estratègies que podien ser utilitzades per ensenyarla. Per exemple, General Science, nascut del moviment "Ciència per a tothom", requeria que els candidats tinguessin algun coneixement dels antecedents històrics de la ciència, però les preguntes d'examen eren poques i limitades a les de caràcter biogràfic (Fowles, 1949, citat per Newton 1988).

A finals dels 1980, quan els EUA van començar el "Project 2061", per formar una generació ben informada i alfabetitzada, la història de la ciència va ser un dels temes inclosos. Tot i així, encara que la idea es va incloure en teoria al pla d'estudis, la història de la ciència només s'afegia al final de les unitats didàctiques, majoritàriament de forma addicional en els llibres de text (Rodger et all, 1991). No obstant això, en aquell moment aquest era el principal problema en discussió. La història de la ciència podia ser tractada des de perspectives diferents, després d'haver estat introduïda en el pla d'estudis, però hi havia problemes dins de la seva integració a la pràctica.

Un dels motius d'aquest problema era que no hi havia un marc i una estratègia real d'ensenyament de la història de la ciència. La segona raó era les mancances dels mestres en relació al tema. Fins i tot els professors que estaven ben informats sobre aquests temes, no trobaven la manera d'integrarlos als processos d'ensenyament (Kim \& Irving, 2009). D'acord amb Matthews (1994) la història de la ciència pot ser integrada al currículum mitjançant la repetició d'experiments històrics, amb la reinterpretació dels debats històrics a través de jocs de rol, d'observacions i de la interpretació de les dades i documents originals, així com la lectura d'històries. En els últims anys, s'han explorat altres formes d'aconseguir-ho, com la STS (sigles en anglès per Tecnologia i Ciència en Societat) i els SSI (Controvèrsies Socio-Científiques), les quals poden començar amb un estudi històric i a continuació examina els temes que ens afecten avui dia mitjançant l'ús de qüestions polèmiques, discussions de 
grup, jocs de rol, resolució de problemes i activitats de lectura en un intent de mostrar la rellevància de la ciència en aquest context social. En fer això, per descomptat, l'educació científica s'humanitza (Newton, 1986).

\section{DISSENYANT LA CIÈNCIA ESCOLAR EN AQUEST CONTEXT}

Presentar la ciència de manera didàctica no és el mateix que presentar allò que fan els científics. És l'anomenada transposició didàctica (Lijnse, 2000), que significa la reconstrucció de la ciència perquè sigui capaç de ser apresa pels alumnes i que està directament relacionat amb el concepte de "ciència escolar." (Izquierdo \& Aduriz-Bravo, 2003). Els científics proposen teories i mètodes per aconseguir els seus propis fins explicatius, però això no és del tot possible per als estudiants a l'escola. La ciència escolar és diferent del que fa el científic i té els seus propis objectius educatius i conceptes teòrics, com ara els processos metacognitius i concepcions dels estudiants. Els estudiants que no són capaços de pensar com els científics, i no tenen els conceptes suficients com per pensar aspectes complicats i complexes (Jiménez Aleixandre, 2010). És un deure de les escoles i dels plans d'estudi proporcionar aquestes habilitats de pensament mitjançant l'ús de diferents enfocaments i materials per als estudiants, com ara en el camp de la naturalesa de la ciència amb la història de la ciència i la filosofia de la ciència.

La planificació de la ciència escolar requereix la inclusió acurada d'idees de ciència (continguts científics) i sobre ciència, i és necessari utilitzar tots els aspectes de la matèria, com ara la modelització, la història, la interacció social, la indagació, etc. La ciència escola hauria de consistir en experimentació, reflexió, preguntes d'investigació i argumentació (Izquierdo \& Aduriz-Bravo, 2003).

$\mathrm{Hi}$ ha grans controvèrsies sobre la cultura del científic i la ciència escolar, ja que s'ha vist que existeix una baixa correlació entre elles (Sorsby, 2001). En aquest context, les persones no requereixen un ampli coneixement de ciència, ni tan sols la capacitat per fer un ús pràctic de la mateixa. Més aviat, el que necessiten és una comprensió de la naturalesa de la ciència - la capacitat d'avaluar el grau de certesa de les afirmacions dels científics, d'avaluar els riscos, d'entendre com produir coneixement científic fiable (Osborne, 2002); de distingir les correlacions de les causes, i la capacitat de traduir i interpretar informes científics comuns que es presenten els mitjans de comunicació. Per tant, creiem que l'ensenyament de la naturalesa de la ciència pot ser un pont important entre la cultura científica i l'escolar.

\section{EL PAPER DE LA NATURALESA DE LES CIÈNCIES: APROPANT LA CIÈNCIA I LA CIÈNCIA ESCOLAR}

El potencial de la Naturalesa de la ciència de servir com un pont entre la cultura associada a la comunitat científica i la resta de la societat fa que sigui un component important.

En primer lloc, perquè la naturalesa de la ciència s'interpreta ara de manera més àmplia, ja que és cada vegada més important com un focus per a l'exploració d'una zona comuna per als historiadors, filòsofs, educadors i científics. La naturalesa de les ciències (NOS en anglès) requereix molt més que històries dels científics i dels seus descobriments, és més com una àrea d'estudi que es compon d'una àmplia xarxa de relacions $\mathrm{i}$ interaccions entre la ciència, la tecnologia i la societat, tant en els contextos històrics i com en els actuals.

Abans de 1985 la preocupació sobre l'educació escolar basada en la NOS estava amb preguntes com "Com la ciència i la tecnologia afecten o han afectat a la societat?", i els mestres il-lustraven això mitjançant l'ús de rareses anecdòtiques, amb històries sobre científics com l'enfocament principal.

Aquestes aproximacions segueixen sent part del contingut de la NOS, però la investigació històrica i sociològica més recent posa més èmfasi en les interaccions subtils, múltiples de la societat, la tecnologia i la ciència, incloent l'efecte de la societat sobre els avenços científics i tecnològics, l'efecte de la tecnologia en la ciència, i vici versa.

A més, l'ensenyament i l'aprenentatge sobre la NOS es pot abordar des de contextos filosòfics, mitjançant l'ús de metodologies que impliquin l'argumentació. Tant per a nens com per adults, és important donar el temps i les estructures per explorar la NOS a través del diàleg i la discussió, tant de ciència com sobre ciència.

En definitiva, allò que l'educació en ciències ha de tractar de desenvolupar és un públic que serà capaç de "llegir" i entendre el discurs de la ciència d'una manera "crítica". En conseqüència, l'ensenyament sobre la NOS no pot ser contingut un extra addicional o un element per afegir varietat, sinó un requisit fonamental d'una educació científica per al proper segle. Només una petita proporció d'estudiants es convertirà en científic, de manera 
que l'objectiu principal de l'educació científica haurà d'anar encaminada sobretot a l'augment de l'alfabetització científica dels nostres estudiants.

\section{BIBLIOGRAFIA}

ATKIN, M. \& BLACK, P. (2007). History of Science Curriculum Reform in the US and in the UK, Chapter 26. Lederman \& Abell (eds). The Handbook of Research in Science Education. Routledge.

BURKE, P. (1978) Popular Culture in Early Modern Europe. Ashgate; 3rd Revised edition edition (May 14, 2009)

Cardinal Principles of Secondary Education, 1918: A Report. Hong Kong: Forgotten Books. (Original work published 1918)

DELORS J. (1996). Education: The Necessary Utopia. Learning The Treasure Within A Report To Unesco Of The International Commission On Education For 21st Century (1996 United Nations Educational, Scientific And Cultural Organization)

Department of Education and Science (DES) (1985) Science 5-16: A statement of Policy HMSO, London.

DRIVER, R., LEACHJ., MILLAR, R. VE SCOTT, P. (1996) Young people's images of science. London: Open University Press.

HIRST, P.H. AND PETERS R.S (1970) The Logic of Education London: Routledge and Kegan Paul

IZQUIERDO, M. \& ADÚRIZ-BRAVO, A. (2003). Epistemological Foundations Of School Science, Science \& Education 12: 27-43, 2003

JIMÉNEZ-ALEIXANDRE, M. P. (2010). 10 ideas clave. Competencias en argumentación y uso de pruebas (p. 200). Barcelona: GRAO.

Kim, S. \& Irving, K (2009). History of Science as an Instructional Context: Student Learning in Gene- tics and Nature of Science. Sci \& Educ (2010) 19:187-215

LIJNSE P (2000), Didactics of Science: the forgotten dimension in science education research? Improving Science Education: The Contribution Of Research by Leach \& Osborne, Chapter 17. The Open University Press, Buckingham, 2000

MATTHEWS, M. (1994). Science Teaching; The Role of History and Philosophy of Science, Routledge, New York, NY., p. 108

NEWTON, D. P. (1986) Humanised science teaching-what is it? School science Review 67,457461 .

NEWTON, D. P. (1988). Making Science Education Relevant. Kogan Page Ltd 120 Pentonville Rd, London N1 9JN. Chapters 1-2-7.

OSBORNE, J. (2002). Learning and Teaching about the nature of science. S. Amos \& R. Boohan (eds.). Aspects of teaching secondary science perspectives on practice (229-237) Routledge

PHENIX, P.H. (1964) Realms of Meaning New York: McGraw-Hill

Qualifications and Curriculum Authority (QCA) (1999). The National Curriculum of England and Wales.

REISS, M. (2001). Teaching science in a multicultural, multi faith society. J. Sears ve P.Sorenson (eds.). Issues in Science Teaching. Routledge.

RODGER W., BYBEE, R, W, POWELL, J, ELLIS, J, GIESE,J LYNN, P. \& SINGLETON, L. (1991). Integrating the History and Nature of Science and Technology in Science and Social Studies Curriculum. Science Education 75(1): 143 -155 (1991)

SORSBY, B. (2001). The irresistable rise of the nature of science in science curricula. J. Sears ve P.Sorenson (eds.). Issues in Science Teaching (23-30) . Routledge. 